\title{
Impaired Colonization and Infection of Tomato Roots by the $\Delta$ frp1 Mutant of Fusarium oxysporum Correlates with Reduced CWDE Gene Expression
}

\author{
Wilfried Jonkers, Christopher D. Andrade Rodrigues, and Martijn Rep \\ Plant Pathology, Swammerdam Institute for Life Sciences, University of Amsterdam, Kruislaan 318, 1098 SM Amsterdam, \\ The Netherlands
}

Submitted 2 October 2008. Accepted 14 January 2009.

\begin{abstract}
The vascular wilt pathogen Fusarium oxysporum f. sp. lycopersici efficiently invades roots and colonizes vascular tissues of its host tomato. For these processes, the F-box protein Frp1 is required. The Fusarium oxysporum $\Delta$ frp1 mutant was characterized in detail to uncover the cause of its colonization defect. Using growth assays, we could attribute poor root colonization to reduced assimilation of organic acids, amino acids (except proline), or polysaccharides, singly or in combination. External root colonization by the $\Delta$ frp 1 mutant is restored by the addition of $0.1 \%$ glucose or proline but infection still does not occur. This is due to the inability of the $\Delta f r p 1$ mutant to penetrate the roots, as demonstrated by the lack of expression of $S I X I$ in the $\Delta$ frpl strain, which is a gene exclusively expressed inside roots, and loss of cell wall-degrading enzyme (CWDE) gene expression. Many of the metabolic defects of the $\Delta$ frp 1 strain can be attributed to reduced expression of the ICLI (isocitrate lyase) gene. Strikingly, an $\Delta i c l 1$ mutant is still fully pathogenic and capable of external root colonization. We conclude that the inability of the $\Delta$ frp 1 strain to colonize and invade roots is not primarily due to metabolic defects but can be attributed to reduced expression of several CWDE genes.
\end{abstract}

For successful infection, a plant-pathogenic fungus needs to adjust its metabolism, morphology, and spectrum of secreted enzymes to allow entry into the plant tissue and growth inside the plant. Sensing the plant environment is probably required to initiate this process. Very little is known about mechanisms required for root colonization and penetration by fungi. These mechanisms are different from those associated with leaf colonization; for example, appressoria are not used to penetrate roots nor are natural openings like stomata present. Currently, metabolic and signal transduction pathways needed for the formation of appressoria are relatively well understood (Wang et al. 2007). Notably, genes required for appressoria formation in Magnaporthe grisea are dispensable for root infection (Sesma and Osbourn 2004). To learn more about the infection process of fungal root pathogens, we study Fusarium oxysporum f. sp. lycopersici, a soilborne fungus that causes wilt disease in tomato plants. It enters the plant through the roots and grows via xylem vessels into the stem, in which the water flow is eventu-

Corresponding author: M. Rep; E-mail: m.rep@uva.nl

* The $e$-Xtra logo stands for "electronic extra" and indicates that a supplementary figure is published online. ally blocked, leading to wilt and, subsequently, death of the plant.

In the earliest stage of infection, a resting structure of a fungal root pathogen, like a chlamydospore of $F$. oxysporum $\mathrm{f}$. sp. lycopersici, senses the proximity of a plant root and starts to germinate. The fungus then needs to obtain nutrients from the plant to be able to rapidly colonize roots, often in competition with other microorganisms.

Initially, root exudate is the only readily available nutrient source for the fungus besides internal energy supplies. Potentially useful nutrients in root exudate of tomato include organic acids with citric, malic, lactic, and succinic acid as the major ones. In lower concentrations, tomato root exudate also contains glucose, xylose, and fructose as the main monosaccharides as well as amino acids (Lugtenberg et al. 2001). Recently, it was shown that the root exudate of tomato as well as some of its individual components can induce germination of Fusarium oxysporum spores (Kamilova et al. 2008; Steinkellner et al. 2005). Root exudate also harbors phenolic compounds, but these appear to be involved in growth inhibition rather than in stimulation (Steinkellner et al. 2005; Taddei et al. 2002).

After germination in the vicinity of roots, a fungus has to adapt its nutrient-acquisition strategy and produce nutritionrelated proteins, ranging from amino acid permeases to cellobiose degradation enzymes. Some of the encoding genes are required for pathogenicity of certain fungi while others are not (Divon and Fluhr 2007). Nutrients from plants can also induce pathogenicity genes in fungi. For Nectria haematococca (Fusarium solani), it was shown that the amino acids asparagine and homoserine from pea roots induce expression of PelD, a pectate lyase (Yang et al. 2005). This is probably relevant for pathogenicity, since deletion of PelD together with PelA, encoding another pectate lyase, reduced virulence (Rogers et al. 2000).

Besides adapting its nutrient acquisition system, a pathogenic fungus also needs to penetrate the root epidermis to infect the plant. Like most fungi, F. oxysporum f. sp. lycopersici produces a broad variety of different enzymes that act on different components of the cell wall (Roncero et al. 2000). For fungi to express cell wall-degrading enzyme (CWDE) genes and assimilate nutrients from plants, it is often necessary to activate alternative (non-glucose) assimilation routes. For instance, the glyoxylate cycle, a bypass of the tricarboxic acid cycle, is necessary to assimilate $\mathrm{C}_{2}$ carbon sources and fatty acids. The ICLI (isocitrate lyase) and MLSI (malate synthase) genes encode enzymes specific for the glyoxylate cycle and are required for virulence in Candida albicans, Stagnospora nodorum, and Magnaporthe grisea (Lorenz and Fink 2001, Solomon et al. 
2004; Wang et al. 2003). Furthermore, use of an ICL promotorgreen fluorescent protein (GFP) fusion to study the pathogen Tapesia yallundae during wheat infection revealed that ICL expression occurred specifically at the plant surface (Bowyer et al. 2000). Peroxisomal metabolic function can also be required for infection, for example for Colletotrichum lagenarium (Kimura et al. 2001), suggesting that beta-oxidation of fatty acids may be important for virulence. For Candida albicans, it was shown that deletion of key enzymes in the pathways of beta-oxidation of fatty acids and gluconeogenesis all confer virulence defects (Ramirez and Lorenz 2007).

To obtain more insight into the process of root infection by fungi and the metabolic requirements for this process, we analyzed in detail the $\Delta f r p l$ mutant of $F$. oxysporum $\mathrm{f}$. sp. lycopersici. FRPl is absolutely required for pathogenicity (Duyvesteijn et al. 2005) and encodes a protein belonging to the class of Fbox proteins that are generally involved in proteasomal protein

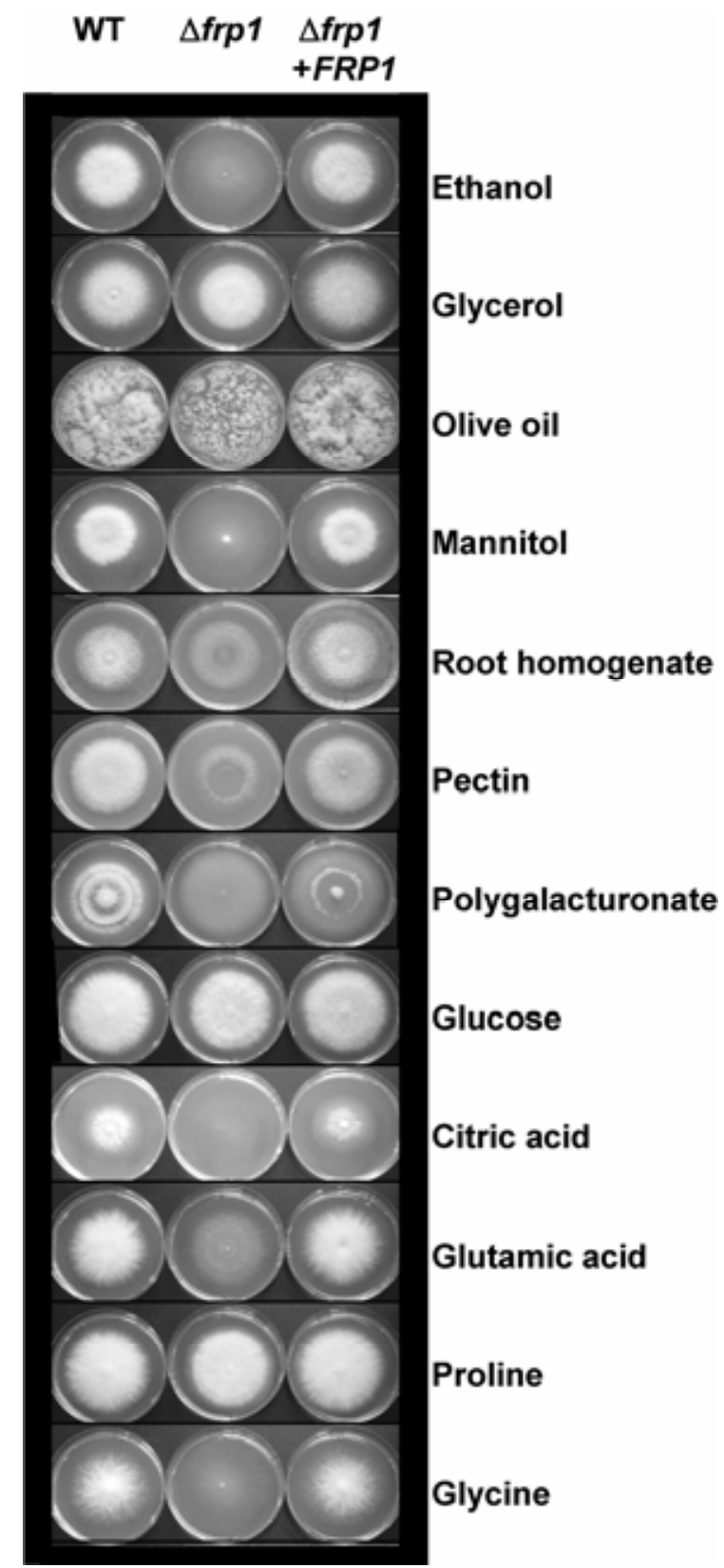

Fig. 1. Growth phenotypes of wild type, $\Delta$ frpl mutant, and the complemented strain on minimal medium agar plates containing different carbon sources. degradation via the ubiquitin conjugation pathway. The function of the F-box protein in this pathway is to bind to a (usually phosphorylated) target protein. The F-box protein and its target assemble into an SCF (Skp1, Cullin, and F-box protein) complex in which the target gets ubiquitinated (Patton et al. 1998).

We show here that colonization of roots is impaired at an early stage in the $\Delta f r p l$ mutant strain. Using growth assays, gene-expression studies, carbon-source supplementation, bioassays, and fluorescence microscopy, we could discriminate different phases of the infection process of $F$. oxysporum $\mathrm{f}$. $\mathrm{sp}$. lycopersici and obtain new insight into the metabolic and physiological requirements for pathogenicity of a fungal root pathogen.

\section{RESULTS}

The $\Delta$ frpl mutant is unable to grow normally on various carbon sources.

Previously, it has been shown that the $\Delta f r p l$ mutant is impaired in root colonization (Duyvesteijn et al. 2005). Since the mutant grows normally on synthetic mediums such as Czapex Dox agar (CDA) and potato dextrose agar (PDA), an explanation for this failure of colonization might be that the mutant cannot assimilate specific nutrients exuded by roots. To investigate this possibility and explore the nutrient assimilation phenotype in general, we tested growth on minimal medium plates containing various carbon sources. We observed that the $\Delta$ frpl mutant is impaired in growth on organic acids, amino acids, fatty acids, alcohols, sugar alcohols, and polysaccharides (Fig. 1; Table 1). The radial growth rate of the $\Delta$ frpl mutant is, in all cases, similar to the wildtype strain, but no or many fewer aerial hyphae are formed. This suggests that the compounds are not toxic to the $\Delta$ frpl mutant but that it has a reduced ability to use these compounds for biomass formation. The $\Delta f r p l$ mutant grows in a similar way as wild type on most monosaccharides and disaccharides and also on glycerol, indicating that the growth defect does not result from a respiration defect but reflects other metabolic problems. Among amino acids, one striking exception was the normal growth on proline. We considered that this might be due to the fact that, in fungi, proline is transported into the cell by a specific transporter, Put4 (Lasko and Brandriss 1981). To test whether Frp1 may influence general amino acid transporters, we grew wild type and the $\Delta f r p l$ mutant on agar plates supplemented with fructose as carbon source and amino acids as the only nitrogen source. This revealed that the $\Delta f r p l$ mutant can still use amino acids as a nitrogen source. With threonine as nitrogen source, for example, the growth of the $\Delta f r p l$ strain is similar to wild type (Fig. 2A). The $\Delta f r p l$ mutant also showed the same sensitivity to the toxic amino acid para-fluoro-phenylalanine (FPA) in concentrations of 10 and $400 \mu \mathrm{M}$ FPA on plates supplemented with $\mathrm{KNO}_{3}$ as nitrogen source and threonine as carbon source. The reduced radial growth in the wild type by increasing amounts of FPA was equally observed in the $\Delta$ frpl mutant (Fig. 2B). Therefore, we consider it unlikely that amino acid transporters are affected in the $\Delta f r p l$ mutant and we conclude that the inability of the $\Delta f r p l$ mutant to efficiently use most amino acids as a carbon source is probably caused by a metabolic defect.

\section{The $\Delta$ frp1 mutant can degrade complex sugars to some extent but is unable} to express several CWDE genes in culture.

Since the $\Delta f r p l$ mutant grows normally on mono- and disaccharides but not on complex sugars, we examined to what extent the expression of genes involved in degradation and assimi- 
lation of polysaccharides is impaired. On agar plates, reduced growth on root homogenate, polygalacturonic acid (PGA), pectin, and xylan was observed (Fig. 1). To study whether the $\Delta$ frpl mutant was able to hydrolyze PGA, a PGA degradation assay was conducted. This assay tests for the production and secretion of polygalacturonases, whose collective activity result in a halo in PGA agar. The $\Delta f r p l$ mutant is capable of forming such a halo even though it is smaller than that of the wild-type strain. This suggests that the $\Delta f r p l$ mutant can secrete polygalacturonases to some extent (Fig. 3A).

To study the expression of individual CWDE genes in more detail, we tested whether the $\Delta f r p l$ mutant is able to express some of the known CWDE genes on inducing medium in vitro. We grew wild type and the $\Delta f r p l$ strains on glucose and then transferred the mycelium to inducing medium (containing pec- tin or PGA). As expected, the wild-type strain induces expression of PL1 (a pectate lyase gene, FOXG_12264.2), PG1 (encoding polygalacturonase 1, FOXG_14695.2), and $P G X 1$ (encoding exo-polygalacturonase 1, FOXG_08862.2) on pectin and PGA medium. In contrast, the $\triangle$ frpl mutant could not visibly induce $P L 1$ on pectin medium nor $P L 1$ or $P G 1$ on PGA medium and showed reduced expression of $P G X 1$ on PGA medium (Fig. 3B).

In conclusion, the $\Delta f r p l$ mutant is unable to grow on many but not all non-sugar carbon sources and is unable to fully express genes needed to degrade the plant cell wall. These deficiencies might underlie its pathogenicity defect. To find out whether this is the case, we next studied the performance of the $\Delta$ frpl mutant at different stages of the infection process and its dependence on specific nutrients at those stages.

Table 1. Growth phenotypes of $\Delta f r p 1$ strain relative to the wild-type stain ${ }^{\mathrm{a}}$

\begin{tabular}{|c|c|c|c|}
\hline Source & $\Delta f r p 1$ vs. wild type & Source & $\Delta f r p 1$ vs. wild type \\
\hline C-source & & Amino acids (Continued) & \\
\hline No carbon source & No differences & Glycine & Strongly reduced \\
\hline No nitrogen source & No differences & Histidine (BDH) & Reduced \\
\hline CDA (Oxoid) & No differences & Leucine (BDH) & Reduced \\
\hline PDA (difco) & No differences but less purple pigment & Phenylalanine (Merck) & Reduced \\
\hline V8 juice agar & No differences & proline & No differences \\
\hline Alcohols & & Threonine (Sigma) & Reduced \\
\hline 1-propanol (Merck) & Less inhibited in spreading & Valine $(\mathrm{BDH})$ & Reduced \\
\hline 2-propanol (Merck) & Less inhibited in spreading, but no aerial hyphae & Oligosaccharides & \\
\hline Allylalcohol (Fluka) & Less inhibited in spreading & Arabinose (Sigma) & Slightly reduced \\
\hline Ethanol (Merck) & Strongly reduced & Fructose (Merck) & No differences \\
\hline Glycerol (Merck) & No differences & Galactose (Duchefa) & No differences \\
\hline Organic acids & & Glucose (Duchefa) & No differences \\
\hline Acetic acid (Merck) & Reduced & Maltose (Sigma) & No differences \\
\hline Ascorbic acid (Merck) & Reduced & Raffinose (Duchefa) & Slightly reduced \\
\hline Citric acid (Merck) & Strongly reduced & Sorbose (L-) & No differences \\
\hline Galacturonic acid & Reduced & Sucrose (Duchefa) & No differences \\
\hline Gluconic acid (Merck) & No differences & Xylose (Sigma) & No differences \\
\hline Lactic acid (BDH) & Strongly reduced & Polysaccharides & \\
\hline Oxalic acid (Merck) & Reduced & Maizena (Duryea) & Reduced \\
\hline Pyruvic acid (Merck) & Strongly reduced & Pectin & Reduced \\
\hline Succinic acid (Merck) & Strongly reduced & Polygalacturonic acid (Sigma) & Reduced \\
\hline Tartaric acid (Merck) & Strongly reduced & Root homogenate & Reduced \\
\hline Fatty acids & & Xylan (oat spelt-) (Fluka) & Reduced \\
\hline Olive oil (Bertolli) & Reduced & Sugar alcohols & \\
\hline Tween 20 (Merck) & No differences in growth, reduced amount of lipid bodies & Inositol (myo) (Merck) & Slightly reduced \\
\hline Amino acids & & Mannitol (Duchefa) & Strongly reduced \\
\hline Alanine (Merck) & Reduced & Sorbitol & Strongly reduced \\
\hline Arginine (Fluka) & Strongly reduced & Xylitol (Merck) & Slightly increased \\
\hline$\gamma$-aminobutyrate (Sigma) & Strongly reduced & Other carbon sources & \\
\hline Glutamate (BDH) & Strongly reduced & Glucosamine (Sigma) & Slightly reduced \\
\hline Glutamine (Merck) & Reduced & Olive oil (Bertolli) & Reduced \\
\hline
\end{tabular}

${ }^{a}$ Grown on minimal medium agar plates containing different carbon sources. Plates were visually assessed. No differences $=$ no different phenotype compared with wild type. Slightly reduced $=$ the $\Delta f r p 1$ strain showed a small reduction in aerial hyphae. Reduced $=$ the $\Delta f r p 1$ strain produced much less aerial hyphae. Strongly reduced $=$ the $\Delta f r p 1$ strain did not produce aerial hyphae. Radial growth was the same in all cases. Supplier names are indicated in brackets.
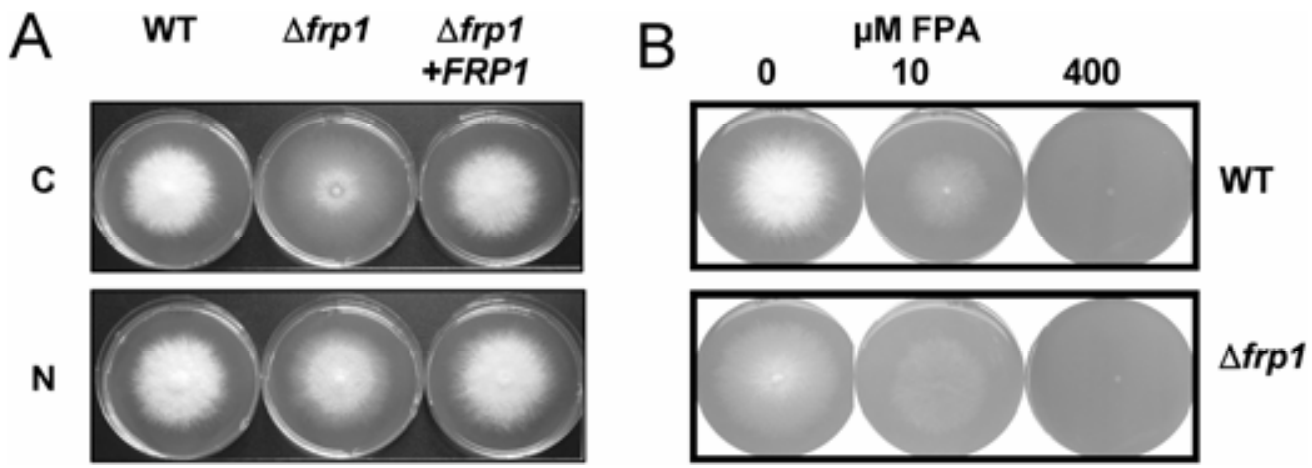

Fig. 2. Reduced growth of the $\Delta f r p 1$ mutant on amino acids is not related to reduced uptake. A, Growth phenotypes of wild type, $\Delta f r p 1$ mutant, and complemented strain on minimal medium agar plates containing threonine as a carbon source $(\mathrm{C})$ or as a nitrogen source $(\mathrm{N})$ ). B, Growth inhibition of wild type and $\Delta f r p 1$ mutant with threonine as a carbon source and with different concentrations of para-fluor-phenylalanine (FPA). 
The $\Delta$ frp1 mutant is able to germinate

in root exudate despite being unresponsive

to citric acid, a major component of root exudate.

The first stage of infection is the germination of spores in response to the proximity of roots. Therefore, we examined the germination efficiencies of wild type and $\Delta f r p l$ mutant in water as well as in soil containing the following additions: root exudate with and without seedlings, glucose, and citric acid. Glucose and citric acid are components of tomato root exudate and are, like root exudate itself, able to induce germination of F. oxysporum (Kamilova et al. 2008; Steinkellner et al. 2005). Germination of either wild type or the $\Delta$ frpl mutant did not occur after 2 days in water or in soil without additives but was prolific in the presence of root exudate or just glucose (Fig. 4). A clear difference in germination rate was observed between wild type and $\Delta f r p l$ mutant in the presence of citric acid. In contrast to the wild type, the $\Delta$ frpl mutant did not germinate in citric acid solutions of either 0.1 or $1 \%$. This correlates to the lack of growth of the $\Delta f r p l$ mutant on agar plates supplemented with citric acid as a carbon source. Tomato root exudate apparently harbors sufficient amounts of other carbon sources to support germination and initial hyphal elongation of the $\Delta$ frpl mutant.

\section{Root colonization by the $\Delta$ frp1 mutant can be restored} by addition of glucose but not by citric acid.

Previous studies with tomato roots inoculated with the $\Delta$ frpl mutant expressing GFP showed strongly reduced colonization compared with wild type (Duyvesteijn et al. 2005). We hypothesized that the inability to proliferate on citric acid and other root exudate components might be the cause of this strongly reduced colonization. To investigate this possibility, we studied fungal colonization on the surface of roots of 10-day-old tomato plants inoculated with GFP-expressing strains in petri dishes. After 5 days, the wild type had colonized the entire root system while the $\Delta$ frpl mutant did not show any root colonization
(Fig. 5, upper panel). Despite being sufficient for spore germination and initial hyphal elongation, the root exudate from the seedlings in the petri dish apparently could not support colonization by the $\Delta f r p l$ mutant.

We then tested whether root colonization could be restored by addition of glucose, proline, or citric acid. Root colonization by the $\Delta$ frpl mutant in the presence of $0.1 \%$ glucose was the same as by the wild type after 5 days, and in both cases, colonization was enhanced compared with water (Fig. 5, middle panel). Addition of $0.1 \%$ proline resulted in massive covering of roots with mycelium by both wild type and the $\Delta f r p l$ mutant after 2 days (data not shown). This is possibly due to the fact that proline acts as both nitrogen and carbon source. Enhanced growth along the roots by the wild type was observed already after 2 days using citric acid, but no colonization of roots was observed in the $\Delta$ frpl mutant (Fig. 5A, lower panel). These observations again correlate with the growth phenotypes on plates. To test whether restoration of root colonization is sufficient for restoration of pathogenicity, seedlings whose roots had been colonized by wild type or the $\Delta f r p l$ mutant in the presence of different amounts of glucose, proline, or citric acid were transferred to pots with soil. Three weeks later, we observed that the wild-type strain had caused severe disease in all cases (Table 2). In contrast, plants inoculated with the $\Delta$ frpl mutant strain looked healthy and no disease symptoms (like vessel browning) were observed (Table 2). To summarize, superficial root colonization of the $\Delta$ frpl mutant can be restored by addition of glucose or proline but the mutant is still unable to cause disease.

\section{The $\Delta f r p 1$ mutant is unable to penetrate tomato roots.}

Given the inability of the $\Delta f r p l$ mutant to cause disease even when root colonization is restored by addition of an external carbon source, we wished to determine whether the mutant can (at least to some extent) invade roots under these conditions. To do this, we made use of the recent observation that the SIXI gene (encoding a small protein secreted in the xylem sap) is
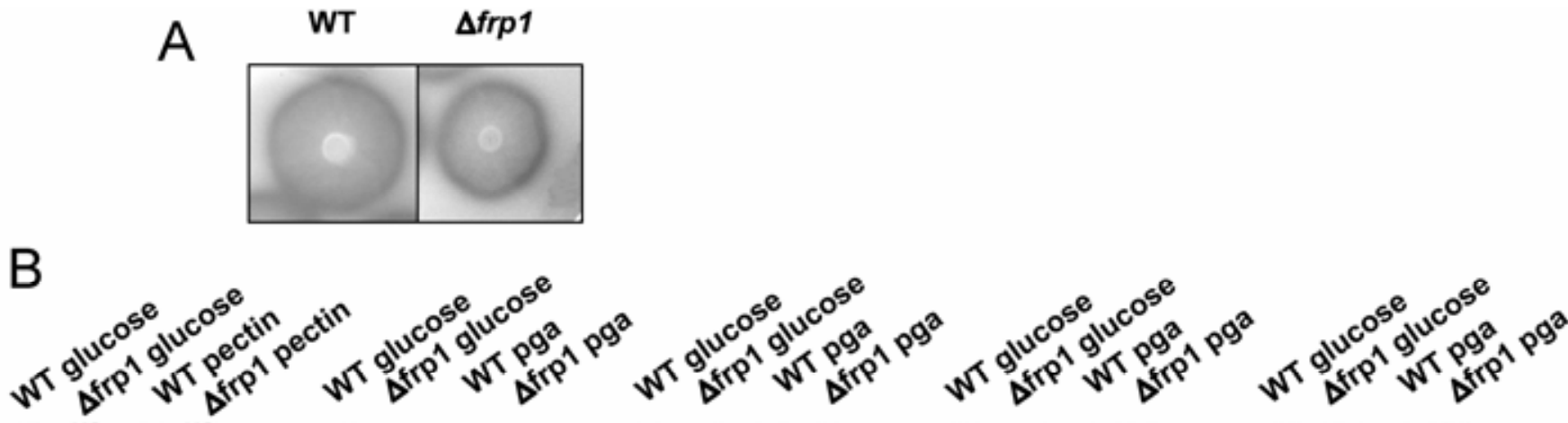

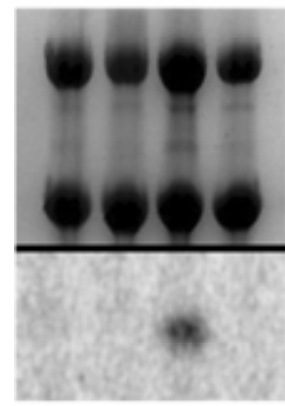

PL1

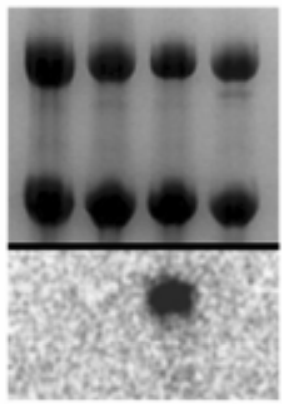

PL1

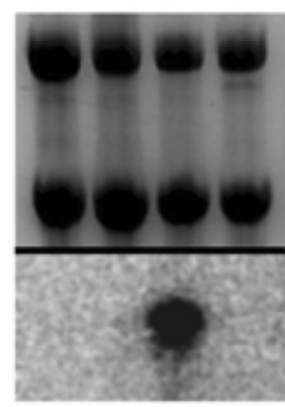

PG1

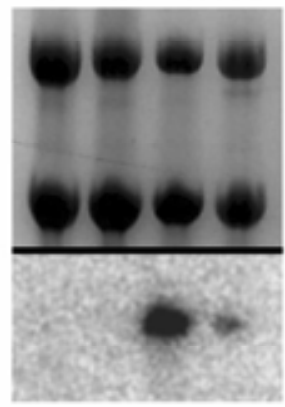

PGX1

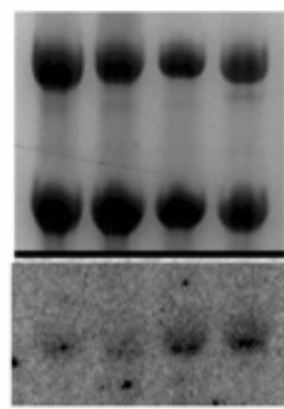

TEF1

Fig. 3. Expression of cell wall-degrading enzyme (CWDE) genes is reduced in the $\Delta$ frpl mutant. A, The halo around the colonies of wild type and $\Delta$ frp1 mutant indicates hydrolysis of polygalacturonic acid (PGA) due to secreted PGA-degrading enzymes. B, Northern blots of RNA from wild type and $\Delta$ frpl mutant growing on glucose or the indicated plant cell-wall components, probed with CWDE gene probes or, as a control, a probe for translational elongation factor 1 alpha (TEF1). Ribosomal RNA bands stained with ethidium bromide indicate equal loading. 
expressed immediately and specifically upon root invasion (van der Does et al. 2008). We used fungal strains derived from wild type as well as the $\triangle$ frpl mutant that express $G F P$ under the control of the $S I X 1$ promotor. In these strains, GFP fluorescence inside roots is an indication that the fungus has entered the roots and has started the production of virulence factors. To first establish whether the $\Delta$ frpl mutant is able to express $S I X 1$, it was cultured together with tomato MSK8 cells in BY medium (Felix et al. 1991). These conditions also result in SIX1 expression (van der Does et al. 2008). Both the wild type and the $\Delta$ frpl mutant can grow in this medium, due to the presence of sucrose, and both can express GFP under these conditions (Fig. 6A), showing that the $\Delta f r p l$ mutant is able to induce $S I X 1$ expression.

After inoculation of tomato roots in petri dishes containing tap water with $0.1 \%$ glucose, using the wild-type strain expressing GFP under the control of the SIX1 promotor, GFPexpressing hyphae were observed in roots as expected (Fig. $6 \mathrm{~B}$, left panel). However, with the $\Delta f r p l$ mutant strain expressing GFP under the control of the $S I X 1$ promotor, no GFP expression was observed, indicating that the $\Delta$ frpl mutant did not enter the root at all (Fig. 6B, right panel).

Penetration of roots may depend on the ability of the fungus to form penetration hyphae (Di Pietro et al. 2001). We found that the $\Delta f r p l$ mutant can penetrate through a cellophane sheet (Supplementary Fig. S1), suggesting that it is able to form penetration hyphae, at least under in vitro conditions. From these results, we conclude that although the $\Delta$ frpl mutant has the ability to penetrate cellophane and express $S I X 1$ in response to plant cells, it lacks the ability to invade roots. We hypothesized that this might be linked to its reduced expression of CWDE genes.

\section{The $\Delta$ frpl mutant does not express}

CWDE genes when growing on roots.

As described above, the $\Delta f r p l$ mutant does not express several CWDE genes in response to cell-wall polymers in vitro. In planta, F. oxysporum f. sp. lycopersici already expresses several CWDE genes in early stages of infection and further throughout the infection cycle (Roncero et al. 2000). This suggests that they may play an important role in the infection process. To be able to analyze the expression of CWDE genes of the $\Delta f r p 1$ mutant on roots, we performed root inoculation experiments in the presence of $0.1 \%$ glucose. This allows the $\Delta f r p 1$ mutant to colonize roots like the wild-type strain. In axenic cultures, CWDE genes can be induced in the wild type in the presence of $0.1 \%$ glucose, demonstrating that this concentration of glucose is not sufficient to cause catabolite repression of CWDE genes (data not shown).

Reverse transcription-polymerase chain reaction (RT-PCR) was performed to compare expression of CWDE genes between the wild-type strain and the $\Delta f r p l$ mutant growing on roots for 1 or 5 days. The constitutively expressed gene FEM1 (Schoffelmeer et al. 2001) was used to compare the amount of fungal RNA in the different samples, using a dilution series. At 1 day, comparable amounts of fungal RNA were isolated, but at 5 days, more fungal RNA from wild-type samples than from $\Delta$ frpl mutant samples was isolated, which can be attributed to extensive growth inside the root system by the wild type. To use equal amounts of fungal template cDNA, a $5 \times$ dilution was used for the wild-type 5-day sample. The results in Figure 7 show that after 1 day, $P G 2, X Y L 2$, and XYL5 expression was present in wild type and absent in the $\Delta$ frpl mutant. After 5 days, $P L 1$ and $P G 1$ expression was present in wild type and absent in the $\Delta f r p l$ mutant sample, similar to induced axenic cultures (a shorter amplified product is seen for PL1 in the $\Delta f r p 1$ mutant lane, but this band proved to be an unspecific product upon sequencing). Expression of another CWDE gene, encoding xylanase 3 (XYL3), was also absent in the $\triangle$ frpl mutant as compared with the wild type. In contrast, $P G X 1$ was expressed in both wild-type and the $\Delta f r p l$ mutant samples, again similar to induced axenic cultures. Interestingly, we found that in both the wild-type and, in the $\Delta$ frpl mutant samples at 1 and 5 days after inoculation, the $X \ln R 1$ xylanase acti-

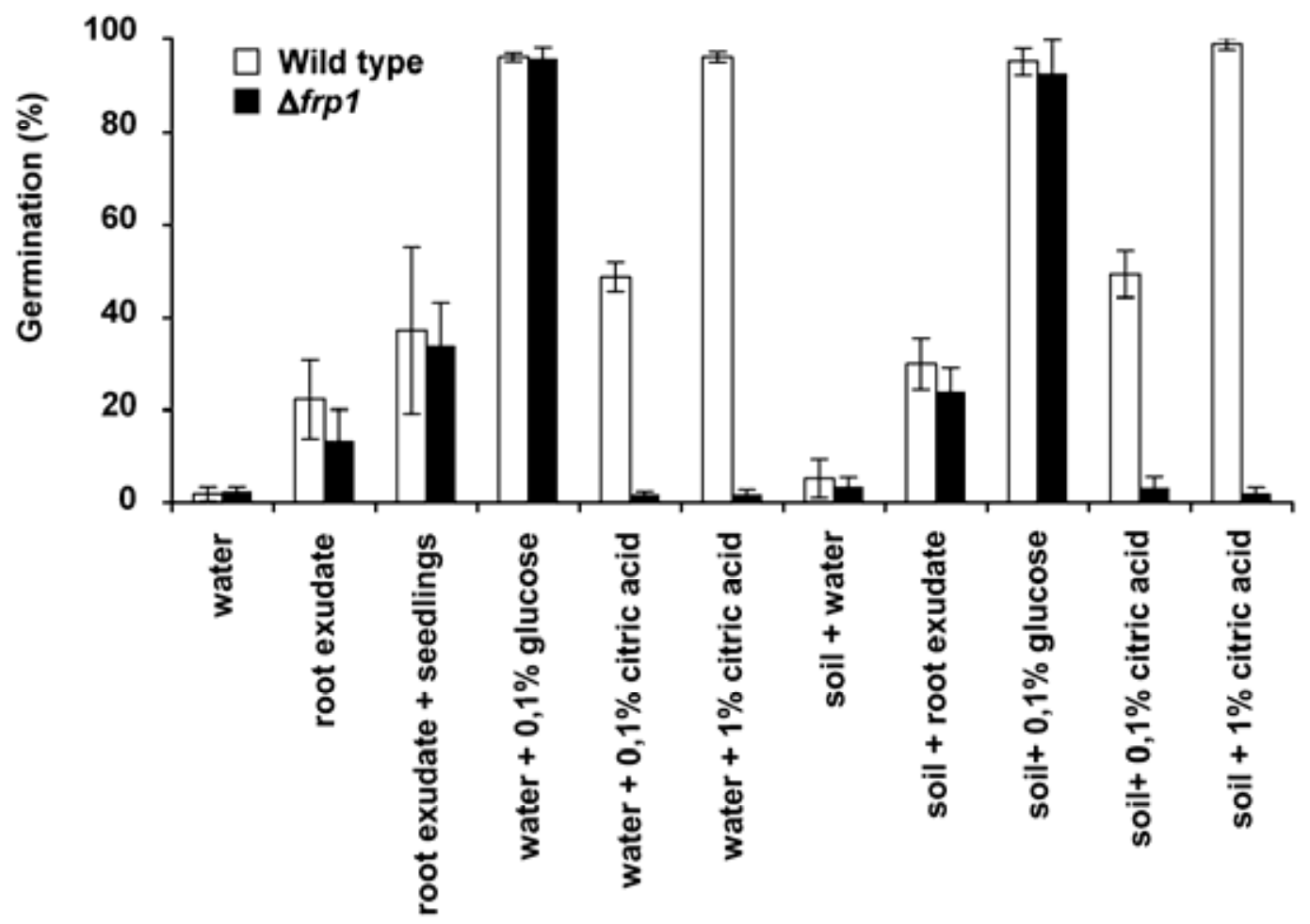

Fig. 4. Spore germination efficiency (percentage of total spores) of wild type and $\Delta f r p l$ mutant in the presence of different nutrients. 
vator gene is expressed. This suggests that lack of expression of XYL2, XYL3, and XYL5 in the $\triangle$ frp1 mutant is not due to absence of this activator. We also confirmed that the $\Delta f r p l \mathrm{mu}$ tant does not express $S I X 1$ or $A R A 1$, encoding an arabinanase found in the xylem sap of infected tomato (Houterman et al. 2007), confirming that the mutant did not enter the roots or reach xylem vessels.

Deficient expression of a set of genes encoding CWDE required to degrade cell walls may be the main cause for the nonpathogenicity of the $\Delta f r p l$ mutant. To exclude an additional role of other metabolic defects caused by loss of Frp1, we constructed an $\Delta i c l l$ mutant that displays similar metabolic defects.

\section{The $\Delta i c l 1$ glyoxylate cycle mutant does not assimilate} a range of carbon sources but is still fully pathogenic.

We considered that the inability of the $\Delta$ frpl mutant to grow proficiently on ethanol or fatty acids as carbon sources could be due to a defect in the glyoxylate cycle. One of the key enzymes of this cycle is isocitrate lyase 1 (encoded by the ICLI gene, FOXG_05529.2). We observed that this gene is indeed expressed in the wild type grown on ethanol or a fatty acid mixture (olive oil) but to a much lower extent in the $\Delta$ frpl mutant (Fig. 8A), explaining the growth defects of the $\Delta$ frpl mutant on ethanol and fatty acids.
To confirm this, we made a knock-out mutant of ICLI and tested this mutant for growth on a panel of different carbon sources. We observed that the $\Delta i c l 1$ mutant, as expected, showed strongly reduced growth on ethanol and fatty acids but, unexpectedly, also on organic acids and sugar alcohols, like the $\Delta$ frpl mutant (data not shown). The growth reduction of the $\Delta$ icll mutant on ethanol and olive oil was even more severe

Table 2. Infection of tomato seedlings with wild type and the $\Delta f r p 1$ mutant $^{\mathrm{a}}$

\begin{tabular}{ll}
\hline & \multicolumn{2}{c}{ Disease observed } \\
\cline { 2 - 3 } Condition & Wild type $\Delta$ frp1 mutant \\
\hline
\end{tabular}

Water

Preincubated in $0.1 \%$ citric acid

Preincubated in $0.1 \%$ glucose

$0.1 \%$ glucose added to soil

Preincubated in $0.1 \%$ proline

$0.1 \%$ proline added to soil

$1 \%$ glucose added to soil

$1 \%$ proline added to soil

${ }^{a}$ Infected with $10^{7}$ spores per milliliter under different conditions. Seedlings were either preincubated for 2 days (citric acid and proline) or 5 days (glucose) and were potted into soil or seedlings were dipped in the spore suspension, were potted into soil, and were supplied every 2 days with the indicated solution of glucose or proline.
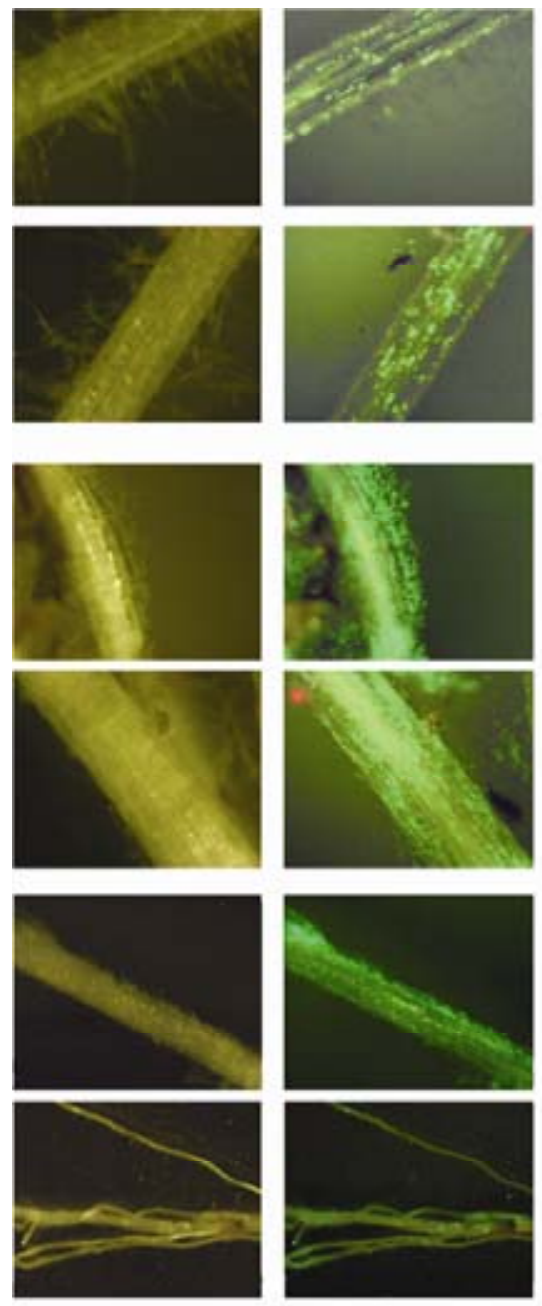

White light
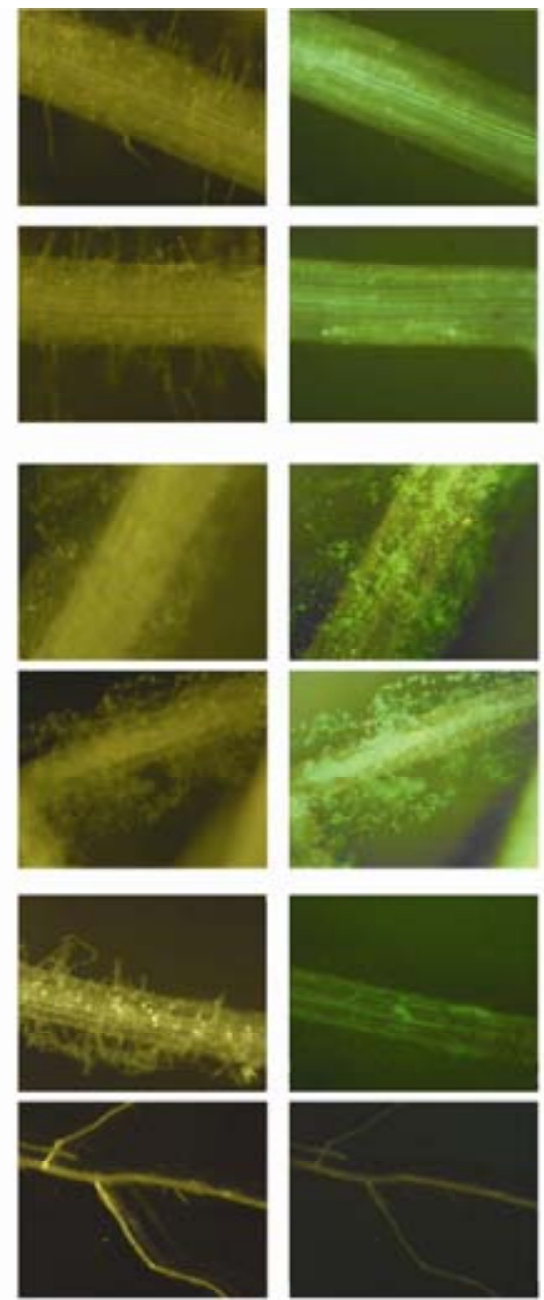

White light

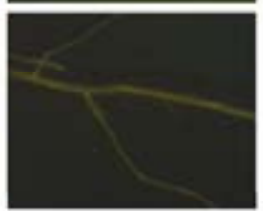

UV-light

\section{Water}

\section{$0.1 \%$ Glucose}

\section{$0.1 \%$ Citric acid}

Wild type

$\Delta$ frp1

Fig. 5. Lack of root colonization by the $\Delta$ frpl mutant can be restored by addition of glucose but not by citric acid. Tomato seedlings were inoculated with the indicated strain in water, $0.1 \%$ glucose, or $0.1 \%$ citric acid. Green fluorescent protein-labeled fungal strains on tomato roots were visualized with UV light using binocular microscopy, after 5 days postinoculation (dpi) (water and glucose) or 2 dpi (citric acid). Pictures are representative of the root system. 


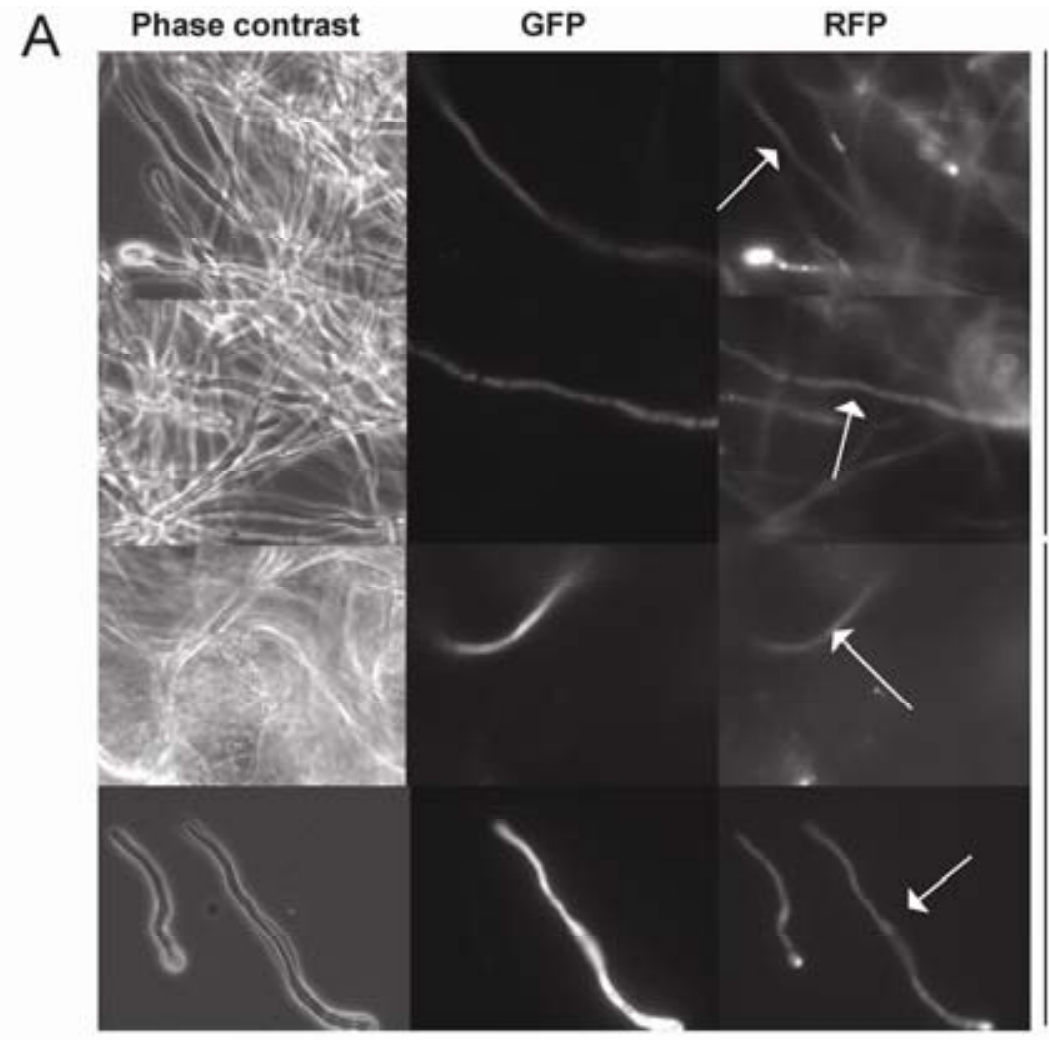

Wild type

$\Delta$ frp1 mutant

B
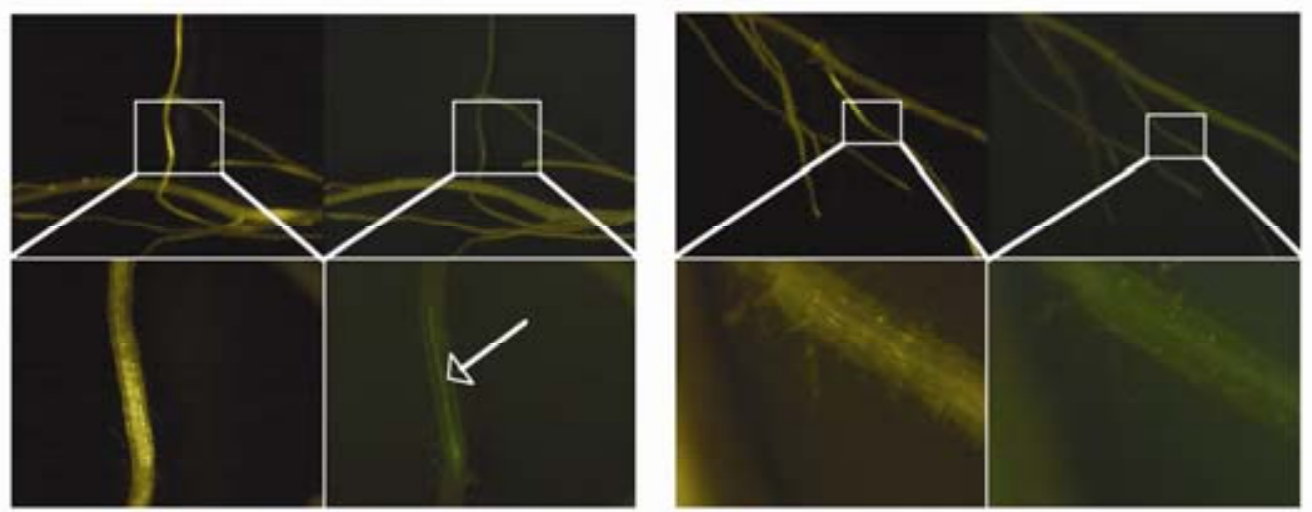

2 dpi
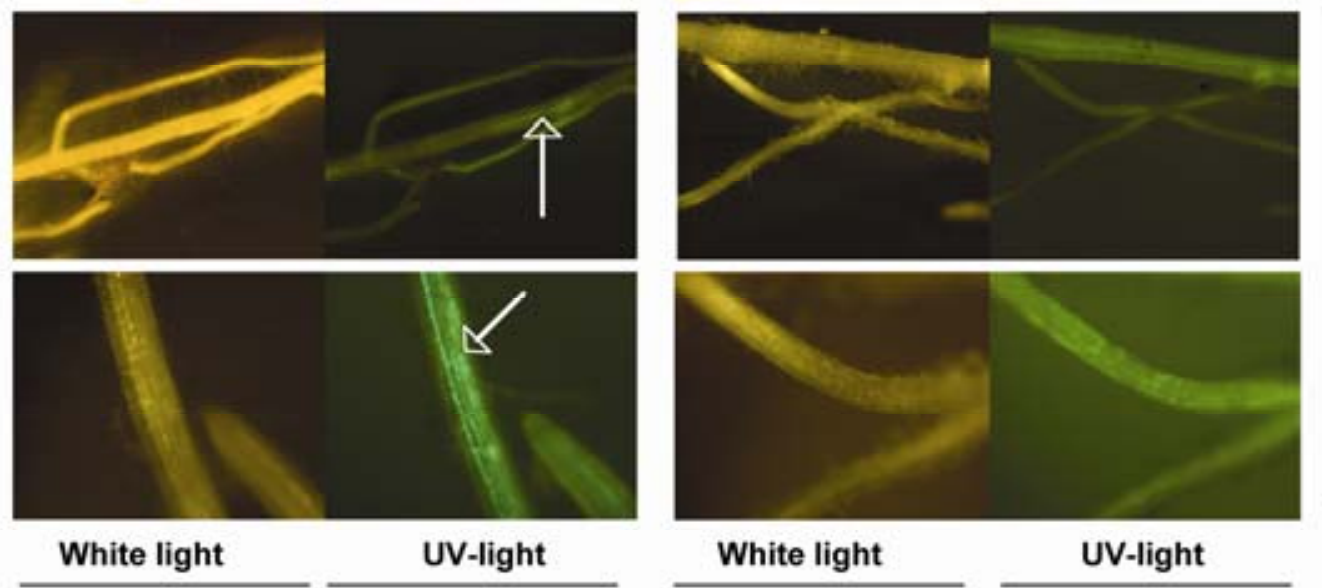

5 dpi

White light

UV-light

WT

\section{Afrp1}

Fig. 6. Absence of SIX1 expression by the $\triangle$ frp1 mutant on roots suggests that the mutant does not penetrate root tissue. A, Fungal strains co-cultured with MSK8 cells showing green fluorescent protein gene $(G F P)$ expression driven by the $S I X 1$ promotor. Arrows indicate $G F P$-expressing hyphae. The pictures in the right panel show constitutive red fluorescent protein gene $(R F P)$ expression from a fusion construct of $R F P$ with the selection marker gene $H P H 1$ behind the constitutive GPD promotor, visualizing all fungal material. The two upper panels show the wild type and the lower panels the $\triangle$ frpl mutant. B, GFP expression in roots as an indication of SIX1 promotor activity. Wild type is shown on the left and the $\Delta$ frpl mutant on the right. Pictures are representative of the root system. 
than that of the $\Delta$ frpl mutant (Fig. 8B). This could be explained by the fact that the $\Delta f r p l$ mutant still maintains a low level of ICL1 expression.

In contrast to the $\Delta f r p l$ mutant, the $\Delta i c l l$ mutant is still able to colonize roots and cause infection (Fig. 8C and D). That expression of ICL1 is not required during the infection process is supported by our observation that ICLI is not expressed in planta at 5 dpi (data not shown). This means that assimilation of ethanol or fatty acids through the glyoxylate cycle is not required for root colonization or pathogenicity of $F$. oxysporum f. sp. lycopersici.

Taken together, we propose that the lack of expression of several CWDE in the $\Delta f r p l$ mutant is the most likely cause of the inability of this mutant to colonize and invade roots.

\section{DISCUSSION}

Our analysis of the pathogenicity defect of the $\Delta$ frpl mutant of the root-invading fungus $F$. oxysporum $\mathrm{f}$. sp. lycopersici has provided new insight into the requirements for root colonization and invasion by fungi. We found that assimilation of carbon derived from the plant is a prerequisite for F. oxysporum $\mathrm{f}$. sp. lycopersici to colonize the roots. The major carbon sources found in root exudate of tomato are organic acids followed by sugars and amino acids (Lugtenberg et al. 2001). Additionally, roots harbor carbohydrates in cell-wall polymers that become available after degradation of the cell wall. Assimilation of

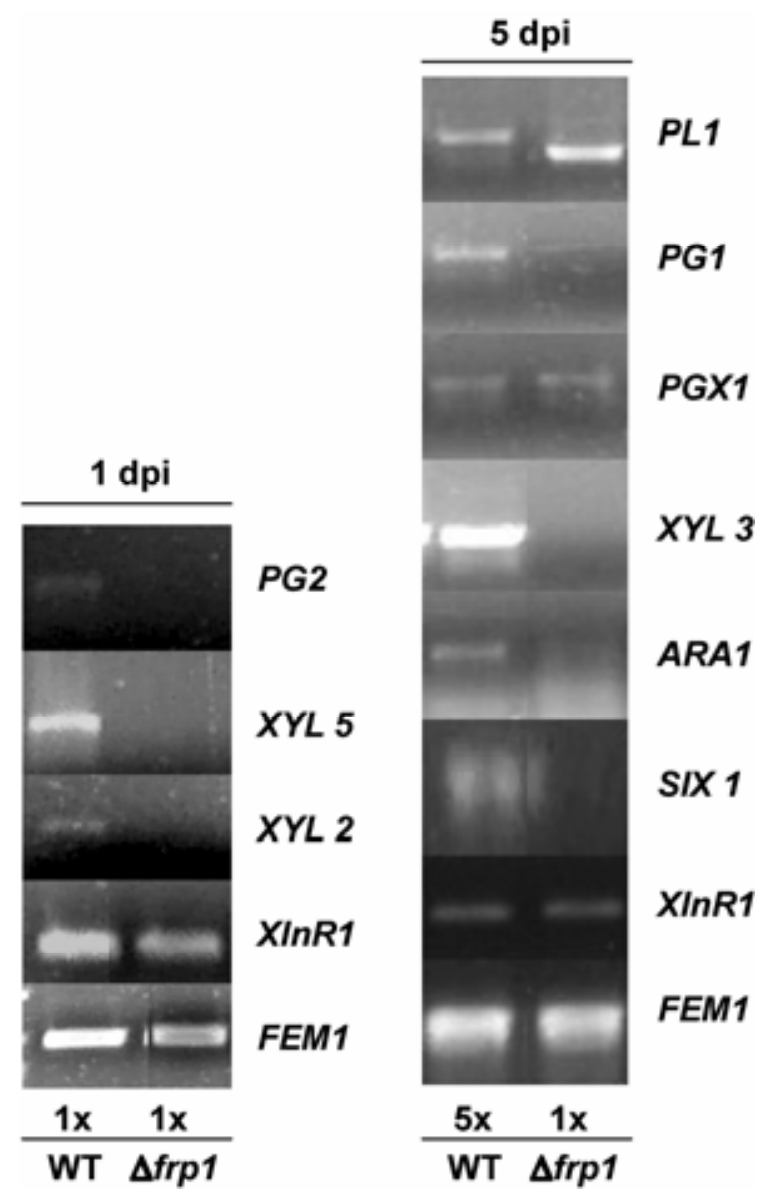

Fig. 7. During root colonization expression of several genes is strongly reduced in the $\Delta$ frpl mutant compared with wild type. Reverse transcriptionpolymerase chain reaction was performed with primers for the indicated genes on RNA from tomato roots colonized by wild type or the $\Delta$ frpl mutant growing in the presence of $0.1 \%$ glucose for 1 and 5 days. The wildtype 5-day sample was diluted five times $(5 \times)$. these nutrients contributes to the rapid growth of the fungus that is probably a prerequisite for infection of the plant.

In this study, we could distinguish between requirements for germination, superficial growth on the root surface, and root penetration. The $\Delta$ frpl mutant is still able to germinate in root exudate, suggesting that Frp1 is not required for this very early stage of the infection process. Germination requires a response from the plant to stimuli (i.e., nutrients), resulting in the germination and adhesion to the host (Osherov and May 2001). The role of stored internal nutrients like fatty acids in spore germination remains unclear. We observed that, although, in both $\Delta f r p l$ and the $\Delta i c l l$ mutant, the assimilation of fatty acids is impaired, they are still able to germinate. Stored nutrients might be dispensable for germination of root-invading fungi because they can immediately assimilate carbon sources from the root exudate to facilitate germination and initial hyphal growth.

The process of superficial root colonization is probably facilitated by the assimilation of carbon sources like citric acid from root exudate but also by cell wall-breakdown products, as the $\Delta i c l l$ mutant does not grow well on organic acids (the major carbon source in root exudate) but still colonizes roots proficiently. When carbon sources are provided externally, the penetration process likely still requires the production of CWDE to break down cell walls and provide entry points.

Taken together, impaired breakdown of polysaccharides by the $\Delta$ frpl mutant seems the most likely cause for both its lack of external colonization and root penetration. This impairment can be ascribed to the strongly reduced expression of several CWDE genes in the $\Delta f r p 1$ mutant. Because of their large numbers and partial redundancy, it has been difficult to study the collective impact of CWDE genes on pathogenicity. Several xylanases, polygalacturonases, and a pectate lyase have been identified, but experiments showed that loss of a single CWDE gene did not affect pathogenicity (Di Pietro et al. 2003; Di Pietro and Roncero 1998; Garcia-Maceira et al. 2000, GomezGomez et al. 2002; Roncero et al. 2000). Additionally, deletion of a CWDE inducer gene, $X \ln R 1$, also showed no effect on pathogenicity (Calero-Nieto et al. 2007).

Another protein involved in the regulation of CWDE gene expression in F. oxysporum is the Snf1 protein kinase. For the $\Delta$ fosnfl mutant of Fusarium oxysporum (Ospina-Giraldo et al. 2003) and the $\Delta$ ccsnfl mutant of Cochliobolus carbonum (Tonukari et al. 2000), it was shown that a set of known CWDE genes was not expressed under inducing conditions. This raises the question whether the Snf1 protein, a protein kinase functioning in carbon catabolite repression in yeast, acts in the same pathway as Frp1. Therefore, we compared the $\Delta f r p 1$ mutant and a snfl mutant obtained from our insertional mutagenesis program (Michielse et al. 2009) in growth assays (data not shown). The snfl mutant showed decreased growth on some sugars, but normal growth was observed on organic acids and amino acids. This suggests that Frp1 and Snf1 act in different pathways affecting nutrient assimilation and reinforces the notion that reduced expression of CWDE genes is the cause for reduced pathogenicity in both mutants.

We have not yet been able to uncover how the Frp1 protein regulates the assimilation of several carbon sources. In general, F-box proteins recruit specific proteins to an SCF complex in which they are labeled with ubiquitin, usually followed by degradation by the proteasome (Kipreos and Pagano 2000). Our efforts to find possible targets of Frp1 have not yet succeeded. Another fungal F-box gene, FBPl, is involved in glucose sensing and controls proteins in the cell-division cycle and sexual development. In Fusarium graminearum, this gene was found to be a virulence factor, presumably because of its function in the degradation of proteins involved directly or indirectly in disease development (Han et al. 2007). That F-box 
proteins are required for pathogenicity may be related to the fact that, for a pathogenic fungus, it is necessary to change cellular functions rapidly and adjust to the environment when invading a host. Such changes and adjustments are processes in which F-box proteins are frequently involved. For example, in Candida albicans, the genes encoding the F-box proteins $\mathrm{CaCdc} 4$ and $C a \mathrm{Grr} 1$ are required for a morphological switch that is important for infection (Atir-Lande et al. 2005; Butler et al. 2006; Shieh et al. 2005).

Our experiments revealed some clues about the biochemical pathways that are affected in the $\Delta f r p l$ mutant. Respiration, the tri-carboxylic acid (TCA) cycle, and gluconeogenesis are still functional in the $\Delta f r p l$ mutant. Assimilation of carbon sources proline and glycerol, on which the growth of the $\Delta$ frpl mutant is not impaired, requires the TCA cycle for generation of ATP and gluconeogenesis for generation of biomass. The reduced growth of the $\Delta f r p l$ mutant on alcohols, organic acids, and sugar alcohols can be attributed to the much lower expression of ICLI in the $\triangle$ frpl mutant, resulting in low flux through the glyoxylate cycle. The major remaining metabolic deficiency in the $\Delta f r p l$ mutant is the reduced ability to use amino acids as a carbon source. This is probably not due to reduced uptake, although a role of amino-acid permeases cannot entirely be ruled out. In Fusarium proliferatum, the first stage of germination and endophytic colonization was adversely affected in the $\Delta f p m t r$ mutant, indicating that amino acid uptake by the permease FpMtr1 might be important for colonization by $F$. proliferatum (Jeney et al. 2007). In plant-pathogenic fungi in general, the utilization of amino acids in the early stage of infection appears to be important to generate energy for rapid proliferation of the fungus (Solomon et al. 2003). In addition, amino acids or catabolic intermediates of amino acid assimilation can induce the expression of colonization and pathogenicityrelated genes, as seen in $F$. solani (Yang et al. 2005). However, since amino acids are only present in small concentrations in root exudate, they are unlikely to play a major role in promoting root colonization by $F$. oxysporum $\mathrm{f}$. sp. lycopersici.

The impaired expression of ICLI and CWDE genes in the $\Delta$ frpl mutant might be caused by a problem in glucose derepression. In yeast and some filamentous fungi, glucose repression inhibits the expression of genes needed for the assimilation of non-sugar carbon sources, activation of secondary metabolism,

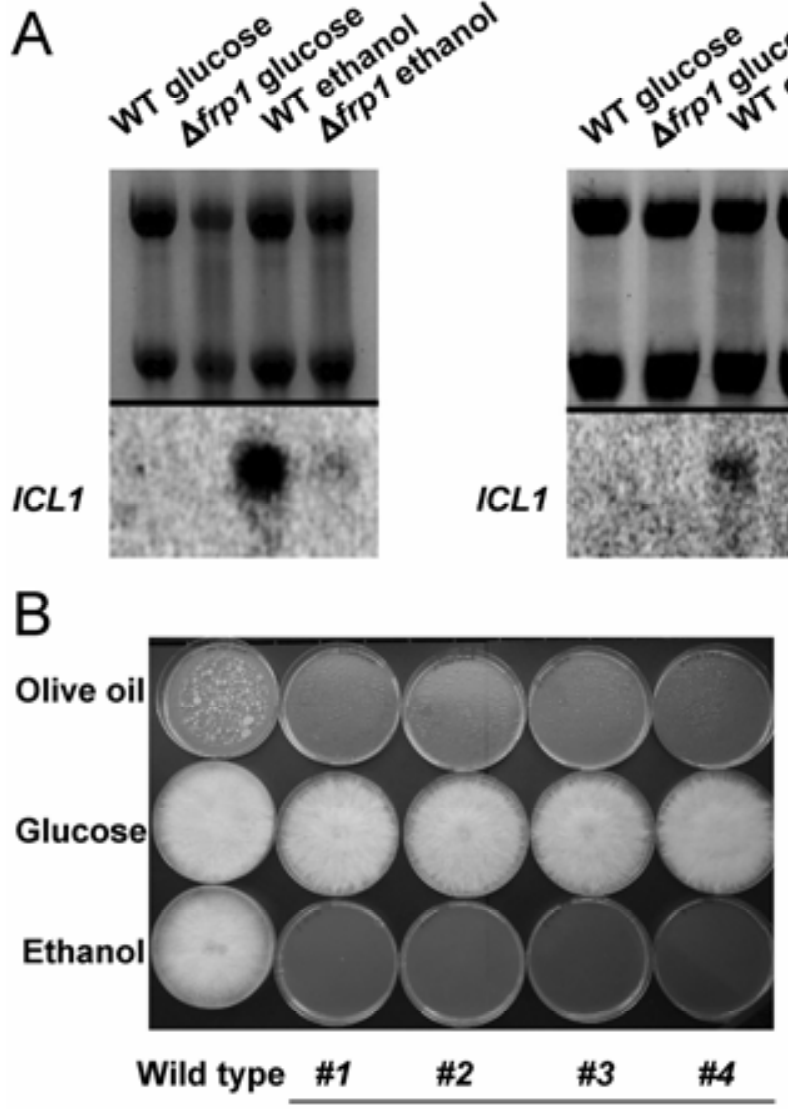

$\Delta i c / 1$
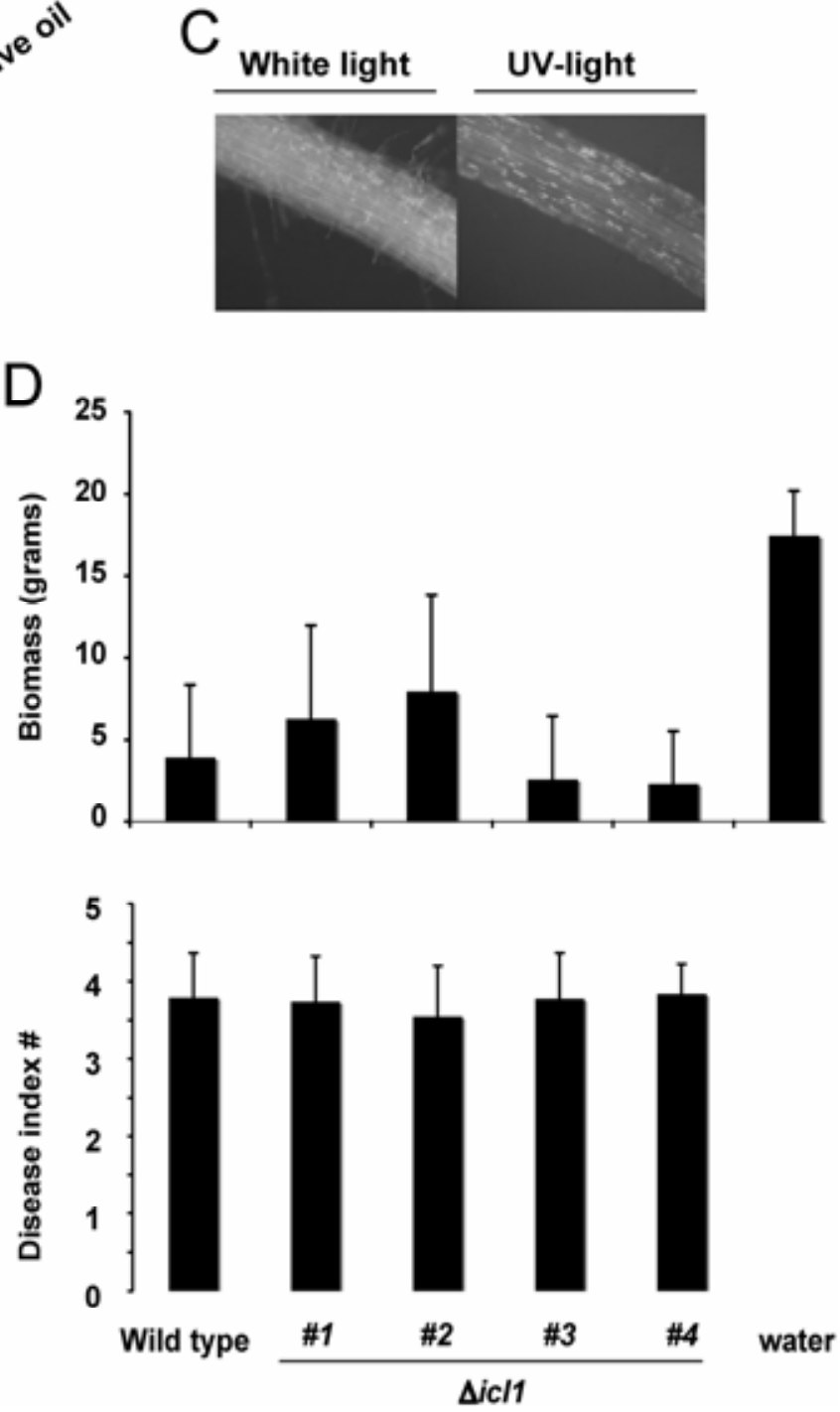

Fig. 8. Expression of $I C L 1$ is strongly reduced in the $\triangle f r p l$ mutant, but $I C L 1$ is not required for colonization or pathogenicity. A, Northern blot of RNA from wild type and $\triangle$ frpl mutant growing on ethanol or olive oil, probed with ICL1. Ribosomal RNA bands stained with ethidium bromide indicate equal loading. B, Wild type and four independent $\Delta i c l 1$ mutants growing on agar plates supplemented with olive oil, glucose, or ethanol. C, A green fluorescent protein-labeled $\Delta i c l 1$ mutant on tomato roots, visualized with UV light using a binocular microscope. D, Weight scores and disease index of tomato plants inoculated with wild type, four $\Delta i c l l$ mutants, or water (mock inoculation). 
expression of CWDE genes, and pathogenicity-related genes (Flipphi et al. 2003; Gancedo 1998; Ronne 1995; Ruijter and Visser 1997). Derepression deficiency in the $\Delta$ frpl mutant may explain the observation that, on plant roots, $X \ln R 1$ was expressed normally in the $\Delta f r p l$ mutant strain, but still, the CWDE genes $X Y L 2, X Y L 3$, and XYL5 were not expressed. It is possible that, in the $\Delta f r p l$ mutant, several CWDE genes are under constitutive repression, preventing the activation of these genes despite the presence of either activator, inducing compounds, or both. A candidate responsible for this effect is CreA, a zinc-finger transcription factor conserved in filamentous fungi (Tonukari et al. 2003; Tudzynski et al. 2000; Vautard et al. 1999). We are currently investigating the role of CreA in the phenotype of the $\Delta$ frpl mutant.

\section{MATERIALS AND METHODS}

\section{Biomaterials and bioassays.}

Fusarium oxysporum f. sp. lycopersici race 2 isolate 007, (Mes et al. 1999a) was used as wild-type strain. Spores from $F$. oxysporum f. sp. lycopersici strains were harvested in $\mathrm{NO}_{3}$ medium $(5 \mathrm{mM} \mathrm{KNO}, 0.17 \%$ yeast nitrogen base [YNB] without amino acids or ammonia [BD, Sparks, MD, U.S.A.] and $3 \%$ sucrose), after shaking for 5 days on a rotary shaker at $150 \mathrm{rpm}$ and $25^{\circ} \mathrm{C}$.

For the germination assays, $1 \mathrm{ml}$ of water containing $10^{7}$ spores was inoculated in flasks containing $20 \mathrm{ml}$ of water, water plus carbon source ( 1 or $0.1 \%$ ), or root exudate collected overnight from tomato seedlings. Alternatively, $10^{7}$ spores in $1 \mathrm{ml}$ water were inoculated on cellophane covered petri dishes filled

Table 3. Primers used in this study

\begin{tabular}{|c|c|}
\hline Name & Primer sequence $\left(5^{\prime}-3^{\prime}\right)$ \\
\hline \multirow[t]{2}{*}{ FRP1 upstrm } & F AAAAAGCTTGGAGTGTCCTCTCCACAGTT \\
\hline & R AAAAAGCTTGGAGTGTCCTCTCCACAGTT \\
\hline \multirow[t]{2}{*}{ FRP1 dwnstrm } & F AAAAGGTACCGCGGATTAAACGGCACCAGT \\
\hline & R TTTTAATTAACTTCCCGCCTCCTATCAAAG \\
\hline \multirow[t]{2}{*}{ ICL1 upstrm } & F AAAAAGCTTCTGCAGGGCCGCATG \\
\hline & R TTTCTAGAGGGCCTCAAGATGTAACTAG \\
\hline \multirow[t]{2}{*}{ ICL1 dwnstrm } & F TTTGGTACCTGCAGGCTCTTCCTCTGAC \\
\hline & R TTTTAATTAAGGATATATTGAAGATGAGTC \\
\hline \multirow[t]{2}{*}{ RFP } & F AAAGGGCCCATGGCCTCCTCCGAGGACGT \\
\hline & R AAAGGGCCCTTAGGCGCCGGTGGAGTGGC \\
\hline FRP1 locus & CTATTGCTCAGATCATCATATC \\
\hline ICL1 locus & GACCAGGTACAGAACTGTCC \\
\hline pPK2-Kpn1 & CCAGAATGCACAGGTACACT \\
\hline \multirow{2}{*}{ PGX } & F ATAACGTTCTTTCGGCGGTC \\
\hline & R ATTGGGCGGTTTCTCATTCG \\
\hline \multirow[t]{2}{*}{ PG1 } & F GCCCGACCATTTCATCGTTG \\
\hline & R GGCACCAGAGGGAATTCCCT \\
\hline \multirow[t]{2}{*}{ PG2 } & F CGTCACCAACTTGGGCGTCT \\
\hline & R ATTGGGCGGTTTCTCATTCG \\
\hline \multirow[t]{2}{*}{ PL } & F AGTACACTGCCATCCTCGCC \\
\hline & R GCAGCTCGTGGTAACTCCA \\
\hline \multirow[t]{2}{*}{ Xyl2 } & F ACGTCGTTAACGAGATCTTCG \\
\hline & R AGCGTTGACAACAGCAGTGTA \\
\hline \multirow[t]{2}{*}{ Xyl3 } & F TTCGCGCAACTCCTTCACCT \\
\hline & R CAGAGCGTTGACCAAGGCAT \\
\hline \multirow[t]{2}{*}{ Xyl5 } & F CCATCTCGTACGAGGGAGAG \\
\hline & R ATTGGCAGGGCTCGTTAGCG \\
\hline \multirow[t]{2}{*}{$\mathrm{X} \ln \mathrm{R} 1$} & F ACGTCTTGCATATTCTATTGG \\
\hline & R GCGCATAACTTTGCTGAATTT \\
\hline \multirow[t]{2}{*}{ SIX1 } & F CCCCGAATTGAGGTGAAG \\
\hline & R AATAGAGCCTGCAAAGCATG \\
\hline \multirow[t]{2}{*}{ ARA1 } & F CATCTCCAACATTGCTACTG \\
\hline & R GCCAAGGTTAGTGTTGATGT \\
\hline \multirow[t]{2}{*}{ ICL1 } & Deg. F GTCTA(G/C)GTTTC(G/C)GGCTGGCA \\
\hline & Deg. R AGCCGAGGAT(A/G)AA(A/G)CATGGT \\
\hline \multirow[t]{2}{*}{ FEM1 } & F AAAGAATTCACCTCCGCCACTGGTGACTC \\
\hline & R AAATCTAGACCGCTCTCAGGGACACTGG \\
\hline
\end{tabular}

with $20 \mathrm{ml}$ of prewetted soil containing water, a carbon source ( 1 or $0.1 \%$ ), and root exudate. Germinated spores were counted in a heamocytometer and were considered germinated when the germination tube was at least as long as the spore. This experiment was performed with three replicates each time.

For plate assays, agar plates were prepared consisting of $\mathrm{NO}_{3}$ medium containing $1.5 \%$ bacto agar and $1 \%$ variable carbon source $(\mathrm{wt} / \mathrm{vol})$ instead of sucrose (Table 1) or fructose medium ( $1 \%$ fructose and $0.17 \%$ YNB) containing $1.5 \%$ bacto agar and $1 \%$ variable nitrogen source (threonine) (wt/vol). Root homogenate was obtained by harvesting tomato root cultures, and after lyophilization, the roots were ground in liquid nitrogen and were stored under sterile conditions.

FPA (Fluka, Buchs, Switzerland) was added to the medium after autoclaving from a sterile stock solution. Plates were inoculated with $2 \times 10^{4}$ spores on the center of the plate, were incubated for 1 week at $25^{\circ} \mathrm{C}$, and were photographed.

The cellophane penetration test (Prados Rosales and Di Pietro 2008) and the PGA degradation assay (Scott-Craig et al. 1990) were performed according to protocol, with minor modifications of the PGA degradation assay, i.e., the $\mathrm{pH}$ was set with $1 \mathrm{M}$ morpholineethanesulfonic acid, pH 5.0 (Duchefa) to an end concentration of $12 \mathrm{mM}$. The plates were incubated for 5 days at $25^{\circ} \mathrm{C}$.

Microscopic examination of root colonization and penetration together with expression studies of GFP in the presence of MSK8 cells in BY medium were performed as described (van der Does et al. 2008). The tomato cultivar C32 (Kroon and Elgersma 1993) was used for the inoculations, and the pictures show a representative part of the root system. Simultaneously, seedlings treated the same way were potted into soil after 2 or 5 days to observe disease developments.

\section{Plant infections.}

The tomato cultivar $\mathrm{C} 32$, which is susceptible to all F. oxysporum f. sp. lycopersici races, was used for the inoculations. Ten-day-old seedlings with cut roots were dipped into a suspension $\left(10^{7}\right.$ spore $\left./ \mathrm{ml}\right)$ and were potted in soil. Biomass and disease index was quantified as described by Mes and associates (1999a) 3 weeks later.

\section{DNA constructs.}

The pPK2 $\triangle$ frpl-GFP plasmid containing a $h p h-G F P$ inframe fusion construct was created by insertion of $1.1 \mathrm{~kb}$ of the upstream flank of FRPI into the HindIII-Xbal sites and $0.45 \mathrm{~kb}$ of the downstream flank into the Pac1-Kpn 1 sites of the pPK2 hph-GFP plasmid (Michielse et al. 2009), using primers FRPI upstrm $\mathrm{F}$ and $\mathrm{R}$ for amplification of the upstream flank and FRPl dwnstrm $\mathrm{F}$ and $\mathrm{R}$ for the amplification of the downstream flank (Table 3), using genomic DNA as a template.

The pPK2 $\Delta i c l-G F P$ plasmid containing the same $h p h-G P F$ fusion construct was created by insertion of $1.1 \mathrm{~kb}$ of DNA of the upstream flank of ICL into the HindIII-Xba 1 sites and $1 \mathrm{~kb}$ comprising the $3^{\prime}$ part of the gene and downstream flank into the Pac1-Kpn 1 sites of the plasmid, using primers ICL1 upstream $\mathrm{F}$ and $\mathrm{R}$ for the amplification of the upstream flank and ICLI dwnstrm $\mathrm{F}$ and $\mathrm{R}$ for amplification of the downstream flank (Table 3), using genomic DNA as a template.

To obtain the $\triangle$ frpl-RFP construct for deletion of FRPI in the $\mathrm{P}_{\mathrm{SIX} 1}-G F P$ strain (van der Does et al. 2008), the two Apa 1 sites flanking GFP in the pPK2 hph-GFP plasmid (Michielse et al. 2009) were used to replace $G F P$ with red fluorescent protein $(R F P)$. The $R F P$ insert was amplified using the primers $R F P \mathrm{~F}$ and $R F P \mathrm{R}$ using a template containing the coding $m R F P$ sequence provided by $\mathrm{R}$. Tsien (University of California, San Diego, U.S.A.) (Campbell et al. 2002). 


\section{Fungal transformations.}

Agrobacterium-mediated transformation was performed as described (Takken et al. 2004). Putative transformants were transferred to CDA (Oxoid, Hampshire, U.K.) containing 100 $\mu \mathrm{g}$ of hygromycin B per milliliter (Duchefa, Haarlem, The Netherlands) and $200 \mu \mathrm{M}$ Cefotaxim (Duchefa). After 4 days, when colonies appeared, spores from putative transformants were suspended in $10 \mu \mathrm{l}$ of sterile water and were spread on PDA (Difco) containing hygromycin B at a concentration of $100 \mu \mathrm{g} / \mathrm{ml}$. Single spore colonies were punched out from the plates by ringcaps (Hirschmann, Eberstadt, Germany) and were placed on fresh PDA plates.

Genomic DNA was obtained from mycelium by extraction with $200-\mu \mathrm{l}$ glass beads, $300 \mu \mathrm{l}$ of phenol/chloroform, and 400 $\mu$ of Tris-EDTA buffer, pH 8.0 , per $1 \mathrm{~cm}^{2}$ of mycelium. Correct gene replacement in the transformants was verified by PCR, using locus primer 'ICLI locus' and 'FRPI locus' and replacement cassette primer pPK2-Kpn1 (Table 3).

\section{Northern blotting.}

Wild type and $\Delta$ frpl mutant were grown in $100 \mathrm{ml}$ of $\mathrm{NO}_{3}$ medium containing $1 \%$ glucose instead of $3 \%$ sucrose for 5 days, shaking on a rotary shaker at $150 \mathrm{rpm}$ and $25^{\circ} \mathrm{C}$; mycelium was harvested over two layers of miracloth (Calbiochem, San Diego, CA, U.S.A.), was washed with sterile water, and was transferred to $100 \mathrm{ml}$ of $\mathrm{NO}_{3}$ medium containing $1 \%$ ethanol, $1 \%$ olive oil, $0.5 \%$ citrus pectin (Fluka), or $0.5 \%$ polygalacturonic acid (Sigma, St. Louis) as a carbon source. After 2 days, the mycelium and spores were harvested over two layers of miracloth, were washed with sterile water, were frozen in liquid nitrogen, and were lyophilized overnight.

Total RNA from lyophilized samples was extracted with TRIzol reagent (Invitrogen, Paisley, Scotland), and samples (15 $\mu$ g RNA) were prepared by $3 \times$ dilution in sample mix (678 $\mu \mathrm{l}$ of formamide (Fluka), $250 \mu \mathrm{l}$ of $37 \%$ formaldehyde (Fluka), $143 \mu \mathrm{l}$ of $10 \times$ morpholinepropanesulfonic acid (MOPS) $(10 \times$ MOPS $=0.2$ M MOPS [Merck, Darmstadt, Germany], $50 \mathrm{mM} \mathrm{NaAc}, \mathrm{pH} 7.0,+20 \mathrm{ml}$ of $0.5 \mathrm{M}$ EDTA per liter, $\mathrm{pH} 8.0$ ), and $1 \times$ sample buffer (50\% glycerol (Merck), $1 \mathrm{mM}$ EDTA, $50 \% \mathrm{H}_{2} \mathrm{O}$, a trace of bromophenol blue (plusOne, Uppsala, Sweden), and $10 \%$ ethidium bromide (Merck). Samples were separated on a formaldehyde gel consisting of $1.1 \mathrm{~g}$ of agarose (Ultra pure, Invitrogen, Carlsbad, CA, U.S.A.), $72 \mathrm{ml}$ of $\mathrm{H}_{2} \mathrm{O}, 18 \mathrm{ml}$ of formaldehyde (Fluka), and $10 \mathrm{ml}$ of $10 \times$ MOPS. Electrophoresis was performed at $40 \mathrm{~V}$ for $20 \mathrm{~min}$ followed by $120 \mathrm{~V}$ for approximately $2 \mathrm{~h}$ in a BRL Horizon 11 horizontal gel electrophoresis system (Gibco, Paisley, Scotland), previously washed with $1 \mathrm{M} \mathrm{NaOH}$ and rinsed with double autoclaved milliQ water. RNA was transferred overnight onto Hybond $\mathrm{N}+$ hybridization membranes following a Northern blot protocol provided by the manufacturer (Amersham Pharmacia Biotech, Piscataway, NJ, U.S.A.).

Probes for the $P G X 1, P G 1$, and $P L 1$ genes were obtained by PCR. Primers for probe amplification (Table 3) were designed based on sequences available in the National Center for Biotechnology Information databases, accession numbers AF083075, U96456, and AF080485, respectively. For amplification of ICL1, degenerated primers (Table 3) were designed based on sequence similarity between Fusarium graminearum, Fusarium verticillioides, Neurospora crassa, and Magnaporthe grisea ICL1 genes, accession numbers XP_390072, CAG28681, CAA44573, and AF540383, respectively.

Probes were labeled with radioactive ${ }^{32} \mathrm{P}$, using the random prime Deca label DNA labeling kit (Fermentas, Vilnius, Lithuania). Northern hybridizations were performed overnight at $65^{\circ} \mathrm{C}$, using Church and Gilbert buffer (Church and Gilbert 1984). Hybridized membranes were washed once at $65^{\circ} \mathrm{C}$ for
$30 \mathrm{~min}$ and were then rinsed twice with $0.5 \times \mathrm{SSC}(1 \times \mathrm{SSC}$ is $0.15 \mathrm{M} \mathrm{NaCl}$ plus $0.015 \mathrm{M}$ sodium citrate) and $0.1 \%$ sodium dodecyl sulfate (vol/wt). Finally, the blots were exposed to a BAS-MIP 2040P imaging plate (Fujifilmm, Tokyo) and were scanned on a STORM 840 (Molecular Dynamics, Sunnyvale, CA, U.S.A.) scanner.

\section{RT-PCR analysis.}

Ten-day-old tomato seedlings were inoculated for 1 and 5 days in tap water with $0.1 \%$ glucose containing $1 \times 10^{7}$ spores per milliliter. The roots from treated plants were cut and were rinsed once with water. Total RNA from freeze-dried samples was extracted with TRIzol reagent (MRC).

Samples were treated with DNAse (Fermentas, Vilnius, Lithuania), and cDNA was produced using the M-MulV reverse transcriptase RNase $\mathrm{H}$ minus kit (Fermentas).

The primers described above (for Northern blotting) were used to analyze gene expression of the $P L 1, P G 1$, and $P G X$ genes. FEM1 was used as an internal control (Schoffelmeer et al. 2001). The primers used for amplification of $P G 2, X Y L 2$, $X Y L 3, X Y L 5, X \operatorname{lnR} 1, S I X 1, A R A 1$, and FEM1 are listed in Table 3.

\section{ACKNOWLEDGMENTS}

We thank L. Reijnen for performing the PGA degradation assay, L. Tikovsky, H. Lamereis, and T. Hendrix for managing the plant growth facilities and assistance with the bioassays, and C. Michielse and B. Cornelissen for critical reading of the manuscript.

\section{LITERATURE CITED}

Atir-Lande, A., Gildor, T., and Kornitzer, D. 2005. Role for the SCFCDC4 ubiquitin ligase in Candida albicans morphogenesis. Mol. Biol. Cell 16:2772-2785

Bowyer, P., Mueller, E., and Lucas, J. 2000. Use of an isocitrate lyase promoter-GFP fusion to monitor carbon metabolism of the plant pathogen Tapesia yallundae during infection of wheat. Mol. Plant Pathol. 1:253262.

Butler, D. K., All, O., Goffena, J., Loveless, T., Wilson, T., and Toenjes, K. A. 2006. The GRR1 gene of Candida albicans is involved in the negative control of pseudohyphal morphogenesis. Fungal Genet. Biol. 43:573-582.

Calero-Nieto, F., Di Pietro, A., Roncero, M. I., and Hera, C. 2007. Role of the transcriptional activator $x \ln R$ of Fusarium oxysporum in regulation of xylanase genes and virulence. Mol. Plant-Microbe Interact. 20:977985.

Campbell, R. E., Tour, O., Palmer, A. E., Steinbach, P. A., Baird, G. S., Zacharias, D. A., and Tsien, R. Y. 2002. A monomeric red fluorescent protein. Proc. Natl. Acad. Sci. U.S.A. 99:7877-7882

Church, G. M., and Gilbert, W. 1984. Genomic sequencing. Proc. Natl. Acad. Sci. U.S.A. 81:1991-1995

Di Pietro, A., and Roncero, M. I. G. 1998. Cloning, expression, and role in pathogenicity of $p g 1$ encoding the major extracellular endopolygalacturonase of the vascular wilt pathogen Fusarium oxysporum. Mol. PlantMicrobe Interact. 11:91-98.

Di Pietro, A., Garcia-MacEira, F. I., Meglecz, E., and Roncero, M. I. 2001. A MAP kinase of the vascular wilt fungus Fusarium oxysporum is essential for root penetration and pathogenesis. Mol. Microbiol. 39:11401152

Di Pietro, A., Madrid, M. P., Caracuel, Z., Delgado-Jarana, J., and Roncero, M. I. G. 2003. Fusarium oxysporum: Exploring the molecular arsenal of a vascular wilt fungus. Mol. Plant Pathol. 4:315-325.

Divon, H. H., and Fluhr, R. 2007. Nutrition acquisition strategies during fungal infection of plants. FEMS (Fed. Eur. Microbiol. Soc.) Microbiol. Lett. 266:65-74.

Duyvesteijn, R. G., van Wijk, R., Boer, Y., Rep, M., Cornelissen, B. J., and Haring, M. A. 2005. Frp1 is a Fusarium oxysporum F-box protein required for pathogenicity on tomato. Mol. Microbiol. 57:1051-1063.

Felix, G., Grosskopf, D. G., Regenass, M., Vasse, C. W., and Boller, T. 1991. Elicitor-induced ethylene biosynthesis in tomato cells: Characterization and use as a bioassy for elicitor action. Plant Physiol. 97:19-25.

Flipphi, M., van de Vondervoort, P. J., Ruijter, G. J., Visser, J., Arst, H. N., Jr., and Felenbok, B. 2003. Onset of carbon catabolite repression in 
Aspergillus nidulans. Parallel involvement of hexokinase and glucokinase in sugar signaling. J. Biol. Chem. 278:11849-11857.

Gancedo, J. M. 1998. Yeast carbon catabolite repression. Microbiol. Mol. Biol. Rev. 62:334-361.

Garcia-Maceira, F. I., Di Pietro, A., and Roncero, M. I. G. 2000. Cloning and disruption of pgx4 encoding an in planta expressed exopolygalacturonase from Fusarium oxysporum. Mol. Plant-Microbe Interact. 13:359-365.

Gomez-Gomez, E., Ruiz-Roldan, M. C., Di Pietro, A., Roncero, M. I., and Hera, C. 2002. Role in pathogenesis of two endo-beta-1,4-xylanase genes from the vascular wilt fungus Fusarium oxysporum. Fungal Genet. Biol. 35:213-222.

Han, Y. K., Kim, M. D., Lee, S. H., Yun, S. H., and Lee, Y. W. 2007. A novel F-box protein involved in sexual development and pathogenesis in Gibberella zeae. Mol. Microbiol. 63:768-779.

Houterman, P. M., Speijer, D., Dekker, H. L., de Koster, C. G., Cornelissen, B. J., and Rep, M. 2007. The mixed xylem sap proteome of Fusarium oxysporum-infected tomato plants. Mol. Plant Pathol. 8:215-221.

Jeney, A., Beki, E., Keszthelyi, A., Leslie, J. F., and Hornok, L. 2007. Cloning and characterization of Fpmtrl, an amino acid transporter gene of Fusarium proliferatum (Gibberella intermedia). J. Basic Microbiol. 47:16-24.

Kamilova, F., Lamers, G., and Lugtenberg, B. 2008. Biocontrol strain Pseudomonas fluorescens WCS365 inhibits germination of Fusarium oxysporum spores in tomato root exudate as well as subsequent formation of new spores. Environ. Microbiol. 10:2455-2461.

Kimura, A., Takano, Y., Furusawa, I., and Okuno, T. 2001. Peroxisomal metabolic function is required for appressorium-mediated plant infection by Colletotrichum lagenarium. Plant Cell 13:1945-1957.

Kipreos, E. T., and Pagano, M. 2000. The F-box protein family. Genome Biol. 1:3002.3001-3007.

Kroon, B. A. M., and Elgersma, D. M. 1993. Interactions btween race 2 of Fusarium oxysporum f. sp. lycopersici and near-isogenic resistant and susceptible lines of intact plants or callus of tomato. J. Phytopathol. 137:1-9

Lasko, P. F., and Brandriss, M. C. 1981. Proline transport in Saccharomyces cerevisiae. J. Bacteriol. 148:241-247.

Lorenz, M. C., and Fink, G. R. 2001. The glyoxylate cycle is required for fungal virulence. Nature 412:83-86.

Lugtenberg, B. J., Dekkers, L., and Bloemberg, G. V. 2001. Molecular determinants of rhizosphere colonization by Pseudomonas. Annu. Rev. Phytopathol. 39:461-490.

Mes, J. J., Weststeijn, E. A., Herlaar, F., Lambalk, J. J. M., WIjbrandi, J., Haring, M. A., and Cornelissen, B. J. C. 1999a. Biological and molecular characterization of Fusarium oxysporum f. sp. lycopersici divides race 1 isolates into separate virulence groups. Phytopathology 89:156-160.

Michielse, C. B., van Wijk, R., Reijnen, L., Cornelissen, B. J., and Rep, M. 2009. Insight into the molecular requirements for pathogenicity of Fusarium oxysporum f. sp. lycopersici through large-scale insertional mutagenesis. Genome Biol. 10:R4.

Osherov, N., and May, G. S. 2001. The molecular mechanisms of conidial germination. FEMS (Fed. Eur. Microbiol. Soc.) Microbiol. Lett. 199:153-160.

Ospina-Giraldo, M. D., Mullins, E., and Kang, S. 2003. Loss of function of the Fusarium oxysporum SNF1 gene reduces virulence on cabbage and Arabidopsis. Curr. Genet. 44:49-57.

Patton, E. E., Willems, A. R., and Tyers, M. 1998. Combinatorial control in ubiquitin-dependent proteolysis: Don't skip the F-box hypothesis. Trends Genet. 14:236-243.

Prados Rosales, R. C., and Di Pietro, A. 2008. Vegetative hyphal fusion is not essential for plant infection by Fusarium oxysporum. Eukaryote. Cell 7:162-171.

Ramirez, M. A., and Lorenz, M. C. 2007. Mutations in alternative carbon utilization pathways in Candida albicans attenuate virulence and confer pleiotropic phenotypes. Eukaryot. Cell 6:280-290.

Rogers, L. M., Kim, Y. K., Guo, W., Gonzalez-Candelas, L., Li, D., and Kolattukudy, P. E. 2000. Requirement for either a host- or pectininduced pectate lyase for infection of Pisum sativum by Nectria hematococca. Proc. Natl. Acad. Sci. U.S.A. 97:9813-9818.
Roncero, M. I., Di Pietro, A., Ruiz-Roldan, M. C., Huertas-Gonzalez, M D., Garcia-Maceira, F. I., Meglecz, E., Jimenez, A., Caracuel, Z., SanchoZapatero, R., Hera, C., Gomez-Gomez, E., Ruiz-Rubio, M., GonzalezVerdejo, C. I., and Paez, M. J. 2000. Role of cell wall-degrading enzymes in pathogenicity of Fusarium oxysporum. Rev. Iberoam Micol. 17:S4753.

Ronne, H. 1995. Glucose repression in fungi. Trends Genet. 11:12-17.

Ruijter, G. J., and Visser, J. 1997. Carbon repression in Aspergilli. FEMS (Fed. Eur. Microbiol. Soc.) Microbiol. Lett. 151:103-114.

Schoffelmeer, E. A., Vossen, J. H., van Doorn, A. A., Cornelissen, B. J., and Haring, M. A. 2001. FEM1, a Fusarium oxysporum glycoprotein that is covalently linked to the cell wall matrix and is conserved in filamentous fungi. Mol. Genet. Genomics 265:143-152.

Scott-Craig, J. S., Panaccione, D. G., Cervone, F., and Walton, J. D. 1990. Endopolygalacturonase is not required for pathogenicity of Cochliobolus carbonum on maize. Plant Cell 2:1191-1200.

Sesma, A., and Osbourn, A. E. 2004. The rice leaf blast pathogen undergoes developmental processes typical of root-infecting fungi. Nature 431:582-586

Shieh, J. C., White, A., Cheng, Y. C., and Rosamond, J. 2005. Identification and functional characterization of Candida albicans CDC4. J. Biomed. Sci. 12:913-924.

Solomon, P. S., Lee, R. C., Wilson, T. J., and Oliver, R. P. 2004. Pathogenicity of Stagonospora nodorum requires malate synthase. Mol Microbiol. 53:1065-1073.

Solomon, P. S., Tan, K. C., and Oliver, R. P. 2003. The nutrient supply of pathogenic fungi: A fertile field for study. Mol. Plant Pathol. 4:203-210.

Steinkellner, S., Mammerler, R., and Vierheilig, H. 2005. Microconidia germination of the tomato pathogen Fusarium oxysporum in the presence of root exudate. J. Plant Interact. 1:23-30.

Taddei, P., Tugnoli, V., Bottura, G., Dallavalle, E., and Zechini D’Aulerio, A. 2002. Vibrational, 1H-NMR spectroscopic, and thermal characterization of gladiolus root exudates in relation to Fusarium oxysporum $\mathrm{f}$. $\mathrm{sp}$ gladioli resistance. Biopolymers 67:428-439.

Takken, F. L., Van Wijk, R., Michielse, C. B., Houterman, P. M., Ram, A F., and Cornelissen, B. J. 2004. A one-step method to convert vectors into binary vectors suited for Agrobacterium-mediated transformation. Curr. Genet. 45:242-248.

Tonukari, N. J., Scott-Craig, J. S., and Walton, J. D. 2000. The Cochliobolus carbonum SNF1 gene is required for cell wall-degrading enzyme expression and virulence on maize. Plant Cell 12:237-248.

Tonukari, N. J., Scott-Craig, J. S., and Walton, J. D. 2003. Isolation of the carbon catabolite repressor (CREA) gene from the plant-pathogenic fungus Cochliobolus carbonum. DNA Seq. 14:103-107.

Tudzynski, B., Liu, S., and Kelly, J. M. 2000. Carbon catabolite repression in plant pathogenic fungi: Isolation and characterization of the Gibberella fujikuroi and Botrytis cinerea creA genes. FEMS (Fed. Eur. Microbiol. Soc.) Microbiol. Lett. 184:9-15.

van der Does, H. C., Duyvesteijn, R. G., Goltsteijn, P. M., van Schie, C. C., Manders, E. M., Cornelissen, B. J., and Rep, M. 2008. Expression of effector gene SIX1 of Fusarium oxysporum requires living plant cells. Fungal Genet. Biol. 45:1257-1264.

Vautard, G., Cotton, P., and Fevre, M. 1999. The glucose repressor CRE1 from Sclerotinia sclerotiorum is functionally related to CREA from Aspergillus nidulans but not to the Mig proteins from Saccharomyces cerevisiae. FEBS (Fed. Eur. Biochem. Soc.) Lett. 453:54-58.

Wang, Z. Y., Soanes, D. M., Kershaw, M. J., and Talbot, N. J. 2007. Functional analysis of lipid metabolism in Magnaporthe grisea reveals a requirement for peroxisomal fatty acid $\beta$-oxidation during appressoriummediated plant infection. Mol. Plant-Microbe Interact. 20:475-491.

Wang, Z. Y., Thornton, C. R., Kershaw, M. J., Debao, L., and Talbot, N. J. 2003. The glyoxylate cycle is required for temporal regulation of virulence by the plant pathogenic fungus Magnaporthe grisea. Mol. Microbiol. 47:1601-1612.

Yang, Z., Rogers, L. M., Song, Y., Guo, W., and Kolattukudy, P. E. 2005. Homoserine and asparagine are host signals that trigger in planta expression of a pathogenesis gene in Nectria haematococca. Proc. Natl. Acad. Sci. U.S.A. 102:4197-4202. 